\title{
Mapeamento terminológico no domínio da radiologia obstétrica: estudo estatístico a partir de ontologias
}

\section{Terminological mapping in the domain of the obstetric radiology: a statistical study based on ontologies}

\section{Mapeamiento terminológico en el dominio de la radiología obstétrica: estudio estadístico a partir de ontologías}

\author{
Igor Soares Amorim ${ }^{1,2, a}$ \\ amorim.igors@gmail.com | https://orcid.org/o000-0003-2606-6000
}

Eduardo Beckhauser ${ }^{1,2, b}$

edubeckha@gmail.com | https://orcid.org/oooo-0002-2001-5635

Vinícius Andreóli Petrolinii, ${ }^{1,2}$

vinicius.petrol@gmail.com | https://orcid.org/oooo-0003-1511-3465

Alexandre Savaris ${ }^{1, c}$

alexandre.savaris@gmail.com | https://orcid.org/o0oo-00o3-0161-6408

Aldo von Wangenheim ${ }^{1,2, d}$

awangenh@gmail.com | https://orcid.org/o0oo-0003-4532-1417

\footnotetext{
Mestrado em Ciência da Informação pela Universidade Federal de Santa Catarina.

${ }^{\text {b } G r a d u a c ̧ a ̃ o ~ e m ~ C i e ̂ n c i a ~ d a ~ C o m p u t a c ̧ a ̃ o ~ p e l a ~ U n i v e r s i d a d e ~ F e d e r a l ~ d e ~ S a n t a ~ C a t a r i n a . ~}$

' Doutorado em Ciência da Computação pela Universidade Federal do Paraná.

${ }^{\mathrm{d}}$ Doutorado em Ciência da Computação pela Universidade de Kaiserslautern.
}

${ }^{1}$ Instituto Nacional de Convergência Digital, Laboratório de Telemedicina. Florianópolis, SC, Brasil.

2 Universidade Federal de Santa Catarina, Programa de Pós-Graduação em Ciência da Computação. Florianópolis, SC, Brasil.

\section{Resumo}

Este artigo tem como base um estudo em que foram levantados e organizados termos do domínio da radiologia obstétrica e, então, foi identificado se os mesmos estão compreendidos em quatro distintos vocabulários controlados: OntoNeo, RadLex, LOINC e SNOMED. É apresentado o Sistema Integrado Catarinense de Telemedicina e Telessaúde (STT/SC) e o projeto de estruturação de laudos de exames de radiologia obstétrica, bem como o contexto teórico da ciência da informação sobre vocabulários controlados. Foram realizadas uma pesquisa de campo para o levantamento dos termos junto a um especialista da área e uma pesquisa documental para o levantamento estatístico dos termos em vocabulários controlados.

Constituiu-se uma hierarquia dos termos levantados e verificou-se a cobertura de cada um dos vocabulários controlados em relação aos termos. O SNOMED é o vocabulário controlado com maior potencial de uso para a indexação de laudos no domínio da radiologia obstétrica.

Palavras-chave: vocabulário controlado; telemedicina; troca de informação em saúde; armazenamento e recuperação da informação; ultrassonografia; radiologia obstétrica. 


\begin{abstract}
This article bases on a study in which terms of the obstetric radiology domain were collected and arranged, and then we identified whether they are comprised in four distinct controlled vocabularies: OntoNeo, RadLex, LOINC and SNOMED. We present the STT/SC - Sistema Integrado Catarinense de Telemedicina e Telessaúde (Santa Catarina's integrated system of telemedicine and telehealth) and the project of structuring diagnostic reports of tests in obstetric radiology, as well as the theoretical context of information science about controlled vocabulary. We carried out a survey of the terms jointly an expert and a documentary research to the statistical survey of the terms from controlled vocabularies. A hierarchy of the terms collected was established and the coverage of each of the controlled vocabularies in relation to the terms was verified. The SNOMED is the controlled vocabulary with greater potential of use for the indexation of diagnostic reports in the field of obstetric radiology.
\end{abstract}

Keywords: controlled vocabulary; telemedicine; health information exchange; information storage and retrieval; ultrasonography; obstetric radiology.

\title{
Resumen
}

Este artículo se basa en un estudio en el cual fueron levantados y arreglados términos del dominio de la radiología obstétrica, y entonces fue identificado si los mismos están comprendidos en cuatro distintos vocabularios controlados: el OntoNeo, el RadLex, el LOINCy el SNOMED. Presentamos el STT/SC - Sistema Integrado Catarinense de Telemedicina e Telessaúde (sistema integrado catarinense de telemedicina y telesalud) y el proyecto de estructuración de resultados de exámenes de radiología obstétrica, así como el contexto teórico de la ciencia de la información sobre vocabularios controlados. Una investigación de campo fue realizada para el levantamiento de los términos junto a un especialista y una investigación documental para el levantamiento estadístico de los términos en vocabularios controlados. Se ha constituido una jerarquía de los términos levantados y se ha verificado la cobertura de cada uno de los vocabularios controlados en relación a los términos. El SNOMED es el vocabulario controlado con mayor potencial de uso para la indexación de los resultados de exámenes en el dominio de la radiología obstétrica.

Palabras clave: vocabulario controlado; telemedicina; intercambio de información en salud; almacenamiento y recuperación de la información; ultrasonografía; radiología obstétrica.

Contribuição dos autores: Concepção e desenho do estudo: Aldo von Wangenheim e Alexandre Savaris.

Aquisição, análise ou interpretação dos dados: Igor Soares Amorim, Eduardo Beckhauser e Vinícius Andreóli Petrolini.

Redação do manuscrito: Igor Soares Amorim, Eduardo Beckhauser e Vinícius Andreóli Petrolini.

Revisão crítica do conteúdo intelectual: Aldo von Wangenheim, Alexandre Savaris e Igor Soares Amorim.

Declaração de conflito de interesses: Não há.

Fontes de financiamento: Secretaria de Estado da Saúde de Santa Catarina - SES/SC.

Considerações éticas: Não há.

Agradecimentos/Contribuições adicionais: Não há.

Histórico do artigo: Submetido: 13.jun.2017 | Aceito: 16.fev.2018 | Publicado: 30.mar.2018

Apresentação anterior: Não há.

Licença CC BY-NC atribuição não comercial. Com essa licença é permitido acessar, baixar (download), copiar, imprimir, compartilhar, reutilizar e distribuir os artigos, desde que para uso não comercial e com a citação da fonte, conferindo os devidos créditos de autoria e menção à Reciis. Nesses casos, nenhuma permissão é necessária por parte dos autores ou dos editores. 


\section{Introdução}

No Brasil, a área interdisciplinar de informação e saúde tem se desenvolvido principalmente a partir do final da década de 1980, influenciada por questões tecnológicas (inserção de tecnologias de informação e comunicação nas instituições de saúde), pela descentralização postulada pela Constituição de 1988, e pela criação de mecanismos de integração entre as esferas municipal, estadual e federal. Tudo isso foi acompanhado da demanda por maior informação, resultando na geração, em 1991, do Datasus (Departamento de Informática do Sistema Único de Saúde) para apoiar o Sistema Único de Saúde (SUS), o qual promove cada vez mais o acesso facilitado a um grande volume de dados de saúde. O desenvolvimento da área implica novas demandas práticas e teóricas ${ }^{1}$.

Nesse contexto, compreendemos o Sistema Integrado Catarinense de Telemedicina e Telessaúde (STT/SC), que visa aplicar tecnologias de informação e comunicação para que processos se tornem mais eficientes. Muitas de suas iniciativas focam a comunicação de serviços de imagem, como ultrassonografia, tomografia computadorizada, ressonância magnética e raio X. O STT/SC provê infraestrutura tecnológica ao núcleo de Telessaúde de Santa Catarina, integrante do programa Telessaúde Brasil Redes do Ministério da Saúde, promovendo serviços de teleconsultoria, tele-educação, telediagnóstico, regulação regional e segunda opinião formativa. Atualmente, todos os municípios de Santa Catarina têm acesso ao STT/SC, e o sistema é mantido pelo Instituto Nacional de Ciência e Tecnologia para Convergência Digital (INCoD) do Departamento de Informática e Estatística (INE) do Centro Tecnológico (CTC) da Universidade Federal de Santa Catarina (UFSC) ${ }^{2}$.

O STT/SC busca a aplicação do padrão Digital Imaging and Communications in Medicine (DICOM) para viabilizar a normalização de procedimentos, da comunicação e do armazenamento de documentos (imagens e/ou laudos estruturados). O padrão DICOM define guidelines para a aquisição, a comunicação e o armazenamento de imagens e laudos, facilitando a interoperabilidade de dados entre sistemas e equipamentos médicos. Tais dados necessitam ser acessíveis e, para tanto, faz-se necessário um sistema de indexação dos mesmos, considerando o uso combinado de diferentes vocabulários controlados.

$\mathrm{O}$ intuito da pesquisa aqui apresentada é viabilizar a interoperabilidade entre vocabulários controlados, de forma a contemplar a indexação e a recuperação de laudos da radiologia obstétrica armazenados pelo STT/SC. Para tanto, objetivamos levantar uma terminologia relativa ao escopo da radiologia obstétrica, sistematizar esse conjunto de termos e mapear a ocorrência destes em vocabulários controlados correntes especificamente na área de radiologia e, de modo mais geral, na área da saúde. Sua justificativa se dá pela otimização dos processos médicos relacionados à emissão de laudos, além da potencialidade de uso dos laudos indexados para pesquisa e produção de conhecimento científico. Ainda, prezamos a interoperabilidade como via mais econômica, visível quando se verifica o dispêndio de recursos necessários à criação de um vocabulário específico para cada subárea contemplada pelo STT/SC.

As duas próximas seções são relativas ao referencial teórico, explicando o que é o STT/SC e o padrão utilizado na estruturação dos laudos médicos e abordando, em seguida, noções e tipologias de vocabulários controlados. Na sequência, uma seção apresenta os procedimentos metodológicos que caracterizam a pesquisa aqui tratada e descreve como o estudo foi conduzido. Em seguida, são apresentados os resultados e discussões numa seção em que se descreve a elaboração de uma estrutura hierárquica de termos do domínio da radiologia obstétrica e se realiza uma comparação destes com os termos recuperados em ontologias mantidas no BioPortal, selecionadas em função dos objetivos da pesquisa. Por fim, são tecidas considerações sobre os resultados obtidos, as limitações deste estudo e a importância de pesquisas futuras. 


\section{Informação e saúde: padronizações em conformidade com o Sistema Integrado Catarinense de Telemedicina e Telessaúde}

O STT/SC foi criado em meados de 2010 com a intenção de unir dois serviços fornecidos no estado: Telemedicina e Telessaúde. Oferece a possibilidade de realização de exames, diagnósticos, cursos, teleconsultoria, conferências à distância via web, além de permitir o acesso dos pacientes aos seus dados.

Telemedicina define-se pela "adoção e utilização de recursos de telecomunicação e outras tecnologias para o compartilhamento de informações médicas referentes a um dado paciente"3, e caracteriza-se pela utilização da tecnologia em serviços médicos que podem superar barreiras geográficas e temporais. Dentre esses serviços, destacam-se o telediagnóstico e a realização de exames de telerradiologia. Quando os mesmos são aplicados corretamente, a telemedicina é vantajosa ao paciente por permitir que sua interação com os médicos seja à distância, sem que precise se locomover para ser atendido.

Telessaúde é o uso da tecnologia de comunicação para a realização dos mais diversos serviços à distância. Como é voltada para a área médica, a mesma possibilita a comunicação e difusão de informação entre os mais variados tipos de profissionais da saúde por meio do acesso remoto a recursos. As principais atividades desenvolvidas são: “a) teleconsultoria: tipo de consultoria realizada entre especialistas que, a partir de um sistema de cadastro de perguntas e respostas, permite a retirada de dúvidas entre dois ou mais profissionais da saúde; b) tele-educação: educação à distância a partir da mediação de recursos didáticos devidamente organizados, apresentados nos mais diversos parâmetros de informação; c) telediagnóstico: utilização de tecnologias para a realização de diagnósticos à distância"4. Este serviço se caracteriza pela emissão de laudos de exames sem que o médico especialista esteja presente no momento da execução do exame.

O STT/SC tem encontrado receptividade junto ao Sistema Único de Saúde e ao Ministério da Saúde, que procura desenvolver a telessaúde desde 2006. O sistema conecta cidades de todo o estado de Santa Catarina, permitindo a otimização de processos variados, tais como exames e conferências. O sistema é viabilizado pela parceria entre a Secretaria de Saúde do Estado de Santa Catarina (SES/SC) e o INCoD (Instituto Nacional de Ciência e Tecnologia para Convergência Digital) vinculado à Universidade Federal de Santa Catarina (UFSC), sendo desenvolvido pelo laboratório de Telemedicina do Hospital Universitário Polydoro Ernani de São Thiago (HU/UFSC). Os serviços do STT/SC concentram-se na coleta, no armazenamento e na disponibilização de dados e informações referentes a exames provenientes de instituições de saúdes sediadas em diferentes municípios do estado ${ }^{3}$. Tais serviços podem ser classificados em quatro processos: a) execução de exames e armazenamento centralizado de seus dados em um repositório; b) disponibilização dos dados para avaliação por especialistas; c) armazenamento de laudos e das opiniões emitidas pelos especialistas sobre esses documentos; d) disponibilização dos resultados das avaliações aos pacientes.

Nesse cenário, a comunicação no STT/SC é fundamental e, neste sentido, a ciência da informação pode corroborar a organização e recuperação dos documentos, além de possibilitar padronizações terminológicas. Este artigo objetiva subsidiar os processos de comunicação no domínio da radiologia obstétrica e a pesquisa que o fundamenta pretende corroborar a estruturação do laudo nesse domínio.

Documentos semiestruturados ou não-estruturados são geralmente de livre preenchimento e idealização, e são de simples utilização. Contudo, há uma série de dificuldades quando se implanta o preenchimento de documentos não-estruturados em sistemas específicos, tais como: questões de padronização terminológica, a suscetibilidade a erros de grafia, a dificuldade de recuperar informações e a dificuldade de gerir os dados contidos nesses documentos e inferir sobre eles.

Documentos estruturados, por outro lado, remetem ao conceito de estruturas organizadas de informação que facilitam a busca do conteúdo, a comparação entre documentos e resultados e a implantação de serviços que ajudam a tomada de decisão quando esses documentos estão devidamente conectados a uma área 
específica. Todo o seu processo de geração até a fase em que são analisados é facilitado pela forma como esse tipo de documento é gerado 5 .

Nesse contexto, laudo estruturado é um documento médico preenchido de acordo com um padrão, predisposto pelo profissional da saúde que o utilizará ou pela instituição na qual ele trabalha, e trará benefícios à comunicação e à pesquisa relacionada ao laudo. Além disso, esses laudos podem ser recuperados, tratados e apresentados de diferentes formas, pois toda a informação neles contida é baseada em dicionários de terminologia controlada que podem ser facilmente identificados em nível sintático e semântico ${ }^{6}$.

O laudo estruturado, no sentido geral de organização, pode ser definido como um conjunto de módulos ${ }^{5,6,7,8}$ :

- Editor de dicionários: responsável pela visualização e edição de dicionários de termos e unidades de medida. Como será descrito, cada item é composto por um par nome-valor, no qual o nome é oriundo de um vocabulário de termos. No caso do foco no qual este trabalho está inserido, o editor de dicionários não será necessário, pois o usuário terá como base todo o conjunto de possíveis vocábulos à sua disposição.

- Editor de templates: permite que usuário construa a hierarquia de modelo de laudo e especifique, para cada item da hierarquia, seu valor, a origem deste valor (dicionário escolhido) e a sua relação com o nodo pai. Depois de construída a hierarquia, esse template é salvo em formato XML (eXtensible Markup Language) e será utilizado na etapa de edição de laudos.

- Editor de laudos: a partir do XML gerado no editor de templates, realizamos a criação de uma interface de forma dinâmica que permite o preenchimento do laudo por parte do médico. Esse preenchimento é salvo em formato DICOM SR (Structured Report), o qual pode futuramente ser visualizado e impresso.

Finalmente, com a estrutura que armazena esse volume de informações, podem-se criar diversos mecanismos facilitadores para o dia a dia do profissional e paciente, tais como:

- padronização de um grande sistema de saúde conforme o mesmo mecanismo de geração de laudos, fazendo com que um laudo possa ser gerado e lido em quaisquer centros de saúde que aderirem à ferramenta;

- eliminação de incertezas inerentes à língua na emissão dos laudos, facilitando futuros diagnósticos e leituras de históricos por parte dos médicos;

- precisão na leitura dos resultados do laudo por parte do paciente, desaparecendo assim com quaisquer dúvidas que possam ser geradas no diagnóstico por texto livre;

- mecanismos de apoio à tomada de decisão, como artifícios de data warehouse, que facilitam a criação dos indicadores citados, não abrangidos pelo modelo operacional de banco de dados . Em outras palavras, a geração de laudos estruturados contribui com a construção de uma ótima base para a realização de estatísticas sobre os dados adquiridos.

Para a estruturação da quantidade potencialmente grande de dados que um laudo estruturado pode gerar, é importante considerar a utilização de algum padrão que resolva os seus impasses perante a formação, a organização e o arquivamento das informações nele adquiridas. Além disso, esse padrão deve dar ao usuário flexibilidade na hora de realizar o procedimento, mas mantendo a estrutura concisa e adequada para posterior manipulação.

O Digital Imaging and Communications in Medicine (DICOM) é um padrão utilizado para a geração, comunicação e arquivamento de imagens médicas digitais. Este padrão estabelece regras para troca de informações médicas entre diversos tipos de equipamentos de imagem e sistemas, estabelecendo uma linguagem comum baseada em protocolos. 
No âmbito geral da pesquisa aqui apresentada, nos interessa mais especificamente a extensão chamada DICOM Structured Report (SR), que define especificamente como devem ser constituídos itens de informação que codificam dados a respeito de exames, diagnóstico e tratamento, além das informações inerentes ao contexto de aplicação, como procedimentos que devem ser executados para o sucesso do tratamento concedido, além de dados sobre os profissionais de saúde envolvidos nos trâmites do processo. Um dito objeto no padrão DICOM pode, então, conter referências a imagens de exames ou outros objetos representados no mesmo padrão ${ }^{8}$.

Uma das principais características que tornam o DICOM SR um padrão robusto é a utilização de terminologias controladas a fim de evitar ambiguidade inerentes à língua, facilitar o entendimento e a recuperação de informações de forma estruturada e simplificada. Um documento DICOM SR, portanto, se caracteriza pela presença de listas com relacionamentos hierárquicos, pelo uso de conteúdo codificado, pelos relacionamentos entre conceitos e pela presença de referências embutidas para imagens e objetos ${ }^{8}$.

Os itens recebem então um indexador codificado. Cada item apresenta no padrão DICOM três faces: seu nome, o qual é um termo para entendimento humano; uma apresentação esquemática; e um código responsável por sua identificação ${ }^{8}$.

Assim o padrão DICOM permite o emprego de vocabulários controlados distintos no mesmo grupo de documentos, pois a cada termo confere um identificador único. Deste modo, possibilita o compartilhamento e o reuso de vocabulários controlados. Buscando uma melhor adequação semântica, a pesquisa em pauta concentrou esforços no mapeamento terminológico de quatro vocabulários específicos: RadLex, LOINC, SNOMED e OntoNeo.

\section{Vocabulário controlado: indexação e classificação}

Tornar pública as informações contidas em registros documentais por meio de algum símbolo intermediário é uma tarefa executada desde mais de dois mil anos antes de Cristo. Os símbolos intermediários “organizam em conjuntos finitos inúmeras informações que se relacionam de alguma forma, mas que se

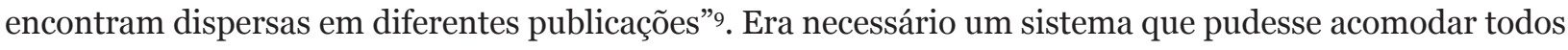
esses intermediários, que eram representações dos registros documentais, pois somente assim o acesso à informação poderia se consolidar de maneira ampla e eficaz. Dessa forma, foram desenvolvidos os sistemas classificatórios bibliográficos, sobretudo entre os anos de 1850 e 1950, quando essa arte adquiriu escopo científico próprio ${ }^{10}$. Inicialmente eram sistemas universais de classificação, que buscavam um ponto de partida neutro para o estabelecimento de taxonomias apriorísticas. Atualmente, a crença na neutralidade está em questão.

Dewey, nos Estados Unidos, e Otlet, na Europa, propuseram no final do século XIX sistemas hierárquicos que pretendiam englobar todo o saber humano, sistematizado em classes decimais e com profunda ramificação. Além de categorizar as representações intermediadoras, tais sistemas seriam utilizados também para ordenar o acervo físico, determinando lugares específicos e demarcados por esses mesmos intermediários, definidos como códigos que designam uma posição permanente dentro da hierarquia dos conhecimentos. Inicialmente, a classificação decimal universal (CDU), de Otlet, não pretendia exatamente isso, mas fundamentalmente, indexar os diferentes assuntos presentes em um único documento, tornando possível a recuperação da informação fragmentada, e não pela unidade documental. Com o cenário pósSegunda Guerra e a disputa entre as duas potências na Guerra Fria, o desenvolvimento econômico, social, científico e militar necessitava ser acelerado. Um forte investimento estatal que integrava todas essas frentes foi ao que se assistiu. Assim, a comunicação científica tornou-se elementar na corrida entre Estados Unidos e União Soviética. Novas ferramentas eram exigidas para o aperfeiçoamento do tratamento e da recuperação 
da informação científica. Essas demandas encontram apoio nos avanços das tecnologias eletrônicas de comunicação, que fora uma das responsáveis pela invenção do computador pessoal e da internet.

Com o aprofundamento das especializações científicas, as classificações que se limitavam às relações hierárquicas e de cunho universalista já não respondiam a essa nova realidade. Nos últimos 30 anos do século XX, a biblioteconomia e a ciência da informação voltaram a atenção para os serviços especializados, buscando tornar a comunicação na pesquisa básica e aplicada mais eficiente. Nesse ensejo, esse campo de atividade incorporou de vez o termo 'informação', sobretudo nos países anglo-saxões, na América Latina e África, o que contribuiu para a legitimação da área enquanto ciência. Estudos da época buscavam melhores formas de organizar as informações não só de livros, mas de patentes, de relatórios técnicos e principalmente de artigos de periódicos científicos. Assim, surge o tesauro, novo instrumento classificador, mais flexível e que permite combinações entre conceitos de diferentes ramos. Nesse instrumento, a relação entre os termos não é apenas hierárquica, mas também associativa; essas relações também não eram mais universais, mas específicas, o que representou um ganho na precisão nos processos de indexação e recuperação da informação. Além disso, os tesauros permitiram que os termos de busca fossem combinados no momento da execução da mesma pelo próprio usuário. Era um avanço importante, que facilitava a rotina de usuários/ cientistas que poderiam ganhar tempo em suas investigações. Nessa altura dos acontecimentos, as buscas já eram feitas em sistemas automatizados, baseados em lógica booleana.

Com o avanço das últimas décadas na área da inteligência e da semântica artificial, novos instrumentos despontam como uma realidade no século XXI: as redes semânticas e as ontologias. Estas mantiveram as especificidades, contudo tornam o processo de recuperação da informação ainda mais inteligente com mecanismos de inferências lógicas que aprimoram os resultados de busca de informação. Atualmente, busca-se nas redes semânticas uma forma de recuperar informações por meio das relações entre conceitos que se estabelecem em nó, e não necessariamente em hierarquia. As ontologias seguem os mesmos direcionamentos, contudo seu horizonte é viabilizar o estabelecimento da web semântica.

A ontologia é considerada um vocabulário controlado de conceitos e suas relações, o qual representa um dado domínio; contudo, somam-se a isso restrições e caracterizações sobre os termos para que estes sejam compreensíveis não apenas a humanos, mas também às máquinas. Assim, as ontologias são compreendidas como elementos fundamentais na construção de uma web capaz de portar semântica sobre os dados e compartilhá-los ${ }^{11}$.

Há sob todo vocabulário controlado um sistema de conceito com algum grau de complexidade. Os sistemas com baixo grau de complexidade não compreendem grande variabilidade de relações entre os conceitos. Um sistema pode mesmo ser uma listagem alfabética de termos, sendo a única regra um critério de seleção que define quais conceitos compõem o sistema. Sistemas mais complexos incorporam outras regras, como as relações hierárquicas, relações não-hierárquicas ou ainda aspectos pragmáticos que delimitam o conceito em um contexto de uso específico.

É entendido que "a qualidade obtida na recuperação da informação depende substancialmente dos procedimentos e instrumentos utilizados para organização da informação" ${ }^{12}$. Portanto, a utilização de um vocabulário controlado mais adequado às necessidades de informação dos usuários de um sistema de informação se faz imprescindível. Entre os tipos possíveis, Bräscher e Carlan ${ }^{12}$ reportam-se aos mais usuais: a classificação, os tesauros, as taxonomias e as ontologias.

A classificação é constituída pelo ato de classificar, ou seja, pela ação de ordenar os elementos diversos em agrupamentos estabelecidos por qualidades de semelhanças e diferenças específicas. Destacamos assim as classificações bibliográficas que se caracterizam como "sistemas predeterminados de conceitos logicamente estruturados e acompanhados de um código identificador"12. Os tesauros "são instrumentos de controle terminológico, utilizados em sistemas de informação para traduzir a linguagem dos documentos, dos indexadores e dos pesquisadores em uma linguagem controlada, usada na indexação e na recuperação 
de informações" ${ }^{12}$. Taxonomias são instrumentos de organização lógica de conteúdos informacionais por meio de classes e subclasses, gerando metadados e padrões que são herdados na hierarquia, podendo ser utilizada para a organização de objetos e conhecimentos, visando dar suporte à navegação em ambiente web, ou ainda como instrumento de auxílio à gestão do conhecimento, sempre enfocando a recuperação da informação. Por fim, ontologias definem "conceitos e relações de alguma área do conhecimento, de forma compartilhada e consensual e promovem e facilitam a interoperabilidade entre sistemas de informação, em um processo 'inteligente' dos agentes (computadores)" ${ }^{12}$; por isso, a ontologia deve se apresentar de maneira formal e legível por computadores, viabilizando o reuso e o compartilhamento de sua estrutura.

No âmbito da saúde, há diversas iniciativas de vocabulários controlados. Muitos desses podem ser encontrados no BioPortal, uma plataforma de compartilhamento e reuso de ontologias desenvolvida pelo National Center for Biomedical Ontology (NCBO), instituição que objetiva apoiar o desenvolvimento dos conhecimentos biomédicos, oferecendo soluções web que promovam pesquisas científicas. O BioPortal é uma biblioteca de terminologias e ontologias biomédicas que visa facilitar o reuso de ontologias ${ }^{13}$. Atualmente o BioPortal é composto por 554 ontologias.

Este trabalho está compreendido no domínio da radiologia obstétrica; assim, buscamos alguns vocabulários no BioPortal que pudessem melhor abranger este domínio, conforme descrito na próxima seção. Há uma tese defendida recentemente por Julietti de Andrade ${ }^{14}$ que se assemelha à pesquisa realizada neste artigo.

\section{Procedimentos metodológicos}

A abordagem da pesquisa aqui apresentada é qualitativa e quantitativa, na medida em que, por meio de trabalhos de estruturação de uma hierarquia junto a um especialista, recuperamos estruturas de vocabulários controlados e realizamos uma análise estatística baseada na concordância terminológica. É de natureza aplicável e de objetivos exploratórios, uma vez que propomos uma hierarquia e exploramos vocabulários selecionados no BioPortal. Ainda quanto aos procedimentos ela é considerada pesquisa de campo, pois constituiu uma seleção de termos e um arranjo segundo consultas a um especialista, e pesquisa de fontes documentais, já que exploramos vocabulários existentes na área médica ${ }^{15,16}$.

Com o intuito de identificar aspectos semânticos e diferentes vocabulários controlados que podem sanar as necessidades semânticas de indexação de laudos na radiologia obstétrica, desenvolvemos a pesquisa em duas etapas principais: a primeira, na qual foi realizada a pesquisa de campo, e a segunda, baseada na pesquisa documental.

Em um primeiro momento, foram realizadas algumas reuniões que serviram para harmonizar nossas intenções com as expectativas do especialista consultado. No decorrer desses encontros, entramos em contato com uma base de dados, desenvolvida pelo próprio especialista, que continha em suas tabelas uma terminologia rica e focava o domínio da ginecologia e da obstetrícia. Foram mapeados os principais termos e, em conjunto com o especialista, selecionamos aqueles relacionados aos exames obstétricos e os organizamos em uma hierarquia, conforme se vê no Apêndice B.

Após essa definição (que passou pela validação da hierarquia pelo especialista), partimos para a segunda etapa, na qual buscamos os termos em vocabulários controlados recuperados no BioPortal. Definimos quatro vocabulários para consulta: RadLex (por ser o principal no âmbito da radiologia), o LOINC (por ser um vocabulário transversal e que contempla diversas áreas), o SNOMED (por sua abrangência) e o OntoNeo (pelo escopo específico e compatível com o nosso foco). O objetivo é analisar quão da nossa hierarquia é contemplado nos vocabulários eleitos no BioPortal. Para tanto, além da identificação dos termos, realizamos uma análise estatística sobre tais resultados. A seguir detalhamos os resultados. 


\section{Resultados e discussões}

Como já mencionado, para realização da primeira etapa da pesquisa de campo, foi organizada uma primeira reunião com um profissional específico, um médico especialista em ginecologia e obstetrícia atuante no Hospital Universitário da UFSC. O médico relatou a necessidade de um sistema automatizado na elaboração de laudos obstétricos, grifando que grande parte das informações contidas em tais laudos são comparações com medidas-padrão. Isso facilitaria a automatização dos laudos que, após estruturados, podem evidenciar as informações padronizadas que são referência para os médicos avaliarem os exames obstétricos.

O especialista nos disponibilizou um arquivo elaborado por ele próprio, um banco de dados em Microsoft Access, o qual contempla toda uma nomenclatura de uso corrente. A partir desse programa, foram listados os termos (Apêndice A). Em seguidas reuniões com o mesmo especialista, os termos foram filtrados. Foram eliminados os que eram relativos à ginecologia e aqueles relativos às patologias (que não estão contempladas no planejamento do atual estágio da pesquisa em pauta). Assim, organizamos a hierarquia de termos validados pelo especialista (Apêndice B).

A hierarquia formulada (Apêndice B) tem uma estrutura já direcionada à estruturação do laudo. Ela apresenta cinco categorias gerais que são subdivididas em subclasses:

- Morfologia: esta categoria destina-se às subclasses relativas às medidas do feto, comumente abordadas como sinais do seu desenvolvimento.

- Doppler: categoria que contempla as medidas de fluxos que são realizadas a partir dos equipamentos Doppler.

- Estática e bem-estar fetal: relativa ao bem-estar geral do feto, como condição muscular (tônus), batimentos cardíacos e posição.

- Anexo fetal: trata dos elementos no entorno do feto, verificando as condições essenciais à saúde do mesmo.

- Exame: dados sobre o exame, relativos aos modos e motivos de aplicação, à sua qualidade, e ao número de fetos.

$\mathrm{Na}$ formulação da hierarquia foi tomada uma decisão a fim de tornar o processo de busca dos termos nos vocabulários controlados previamente selecionados mais efetiva. Optamos pela decomposição dos termos em partes menores, porque foi constatado que a busca realizada no BioPortal é dotada de uma inteligência que, a partir da menor parte do termo, sugere outros termos alternativos que apresentam terminologia semelhante. O processo de decomposição é evidenciado por uma comparação entre o apêndice A e B. Com isso, obtivemos resultados mais efetivos na busca, possibilitando recuperar informações consideradas aproximadas. 
Tal decomposição dos termos resultou em uma ramificação das subclasses findada em termos conclusivos. Assim, observamos que, em diversos ramos, os elementos chamados de folha na estrutura terminam em termos 'alterado' ou 'normal', tal como no exemplo extraído do Apêndice B:

Quadro 1. Fragmento da hierarquia 1

\begin{tabular}{|l|l|}
\hline A2.3 & biparietal \\
\hline A2.3.1 & diâmetro \\
\hline A2.3.1.1 & alterada \\
\hline A2.3.1.2 & normal \\
\hline A2.4 & cefáfica \\
\hline A2.4.1 & circunferência \\
\hline A2.4.1.1 & alterado \\
\hline A2.4.1.2 & normal \\
\hline
\end{tabular}

Fonte: Os autores (2018).

No Quadro 1 notamos que a medida da circunferência cefálica pode estar alterada ou normal. Quando alterada, interessa saber qual o motivo e o nome da patologia a ser tratada.

No atual estágio do trabalho, não exploramos os termos relativos às patologias, o que será feito em uma próxima etapa. Por isso, mantemos por hora a nomenclatura 'alterado' e 'normal', o que acontece nas subclasses A1.2.1.1; A1.2.1.2; A1.3.1.1; A1.3.1.2; A1.4.1.1; A1.4.1.2; A1.5.1.1; A1.5.1.2; A2.1.1.1; A2.1.1.2; A2.2.1.1; A2.2.1.2; A2.3.1.1; A2.3.1.2; A2.4.1.1; A2.4.1.2; A2.5.1.1; A2.5.1.2; A2.5.2.1; A2.5.2.3; A2.7.1.1; A2.7.1.2; A2.8.1.1; A2.8.1.2; A2.9.1.1; A2.9.1.2; A2.10.1.1; A2.10.1.2; A2.11.1.1; A2.11.1.1; A2.12.1.1; A2.12.1.2; A2.13.1.1; A2.13.1.2; A2.14.1.1; A2.14.1.2; A2.15.1.1; A2.15.1.2; B1.1.1; B1.1.2; B1.2.1; B1.2.2; B2.1.1; B2.1.2; B2.2.1; B2.2.2; B3.1.1; B3.1.2; B3.2.1; B3.2.2; B4.1.1; B4.1.2; B4.2.1; B4.2.2; C8.1; C8.2; D1.2.1.4; D1.2.1.5.

O mesmo se aplica aos termos 'ausente' e 'presente', conforme as subclasses $\mathrm{C}_{2.1}$; C2.2; $\mathrm{C}_{5}$.1; $\mathrm{C}_{5.3}$; C7.1.1; C7.1.2; C7.2.1; C7.2.2; com os termos 'regular' e 'irregular' designados pelos códigos A2.6.1.1; A2.6.1.2; C5.2; C5.4; e, por fim, os termos 'aumentado' e 'diminuído', que se encontram em D2.1.5; D2.1.6 (ver Apêndice B).

Além disso, o processo de decomposição nos permitiu a identificação de termos que poderão ser considerados como 'modificadores' na estruturação do laudo, a depender da avaliação das vantagens e desvantagens de incluir tais termos como indexadores presentes em vocabulários controlados ou como elementos que condicionam os substantivos designadores dos campos. Nesse conjunto, os mais recorrentes são 'comprimento', que ocorre 12 vezes, encontrando-se nas subclasses A1.5.1; A2.1.1; A2.2.1; A2.7.1; A2.8.1; A2.9.1; A2.10.1; A2.11.1; A2.12.1; A2.13.1; A2.14.1; A2.15.1; 'pulsatilidade', que aparece em B1.1; B2.1; B3.1; B4.1, ou seja, quatro vezes; os termos 'distância' e 'resistência', que se revelam respectivamente em três subclasses, A1.2.1; A1.3.1; A1.4.1 e B1.2; B2.2; B4.2, portanto , três vezes cada um. Ainda há outros termos com apenas uma ocorrência e que se enquadram nesse conjunto, tal como 'diâmetro' (A2.3.1), 'condição' (A2.6.1) e 'circunferência' (A2.4.1) (ver Apêndice B). 
Os conceitos principais da hierarquia proposta se concentram nas classes de segundo nível da classificação expostas no Quadro 2, pois são dessas classes que as outras informações são atributos, derivadas ou são as classes às quais elas se referem.

\section{Quadro 2. Fragmento da hierarquia 2}

\begin{tabular}{|l|l|}
\hline A & Morfologia \\
\hline A1 & Medida Facial \\
\hline A2 & Biometria Fetal \\
\hline B & Doppler \\
\hline B1 & umbilical \\
\hline B2 & cerebral \\
\hline B3 & Ducto Venoso \\
\hline B4 & Artéria uterina \\
\hline C & Estática e Bem-estar Fetal \\
\hline C1 & Dorso \\
\hline C2 & tônus \\
\hline C3 & Apresentação \\
\hline C4 & Posição \\
\hline C5 & Batimento Cardíaco fetal \\
\hline C6 & Cardiotocografia \\
\hline C7 & Movimento \\
\hline C8 & Genital \\
\hline D & Anexo Fetal \\
\hline D1 & Placenta \\
\hline D2 & Líquido amniótico \\
\hline E & Exame \\
\hline E1 & via de exame \\
\hline E2 & qualidade de exame \\
\hline E3 & Gestação \\
\hline E4 & Indicação \\
\hline & \\
\hline
\end{tabular}

Fonte: Os autores (2018).

Embora as informações principais se refiram às classes expostas no Quadro 2, destacamos ainda as subclasses derivadas de A1 - 'Medida facial' e A2 - 'Biometria fetal', pois as classes filhas de A1 e A2 representam partes do sistema ósseo e outros órgãos dos quais a medida em relação ao padrão médio é fundamental para os exames de radiologia obstétrica.

Essa hierarquia foi estabelecida mediante o contato direto com o especialista, que a validou. Após essa etapa, adentramos na pesquisa documental para o reconhecimento nos vocabulários controlados que estabelecemos como viáveis: o RadLex, o LOINC, o SNOMED e o OntoNeo. 
Desenvolvido pela Radiological Society of North America (RSNA), o RadLEx é um vocabulário extenso, com cerca de 68 mil termos, que visa servir de base para a comunicação online de imagens, relatórios de imagem e registros médicos no âmbito da radiologia ${ }^{17}$. O LOINC é um vocabulário voltado para as observações clínicas e laboratoriais, e é estruturado a partir de seis categorias principais: component, property, time, system, scale, and method ${ }^{18}$. O SNOMED é uma ferramenta internacional e multilíngue bastante abrangente que visa subsidiar a indexação de registros clínicos do paciente que contenham sinais, sintomas, diagnósticos, procedimentos, anatomia, patologias, entre outras manifestações ${ }^{19}$. Já o OntoNeo é um projeto recente que busca a superação de falhas relativas à interoperabilidade semântica entre sistemas de informação por meio do uso de diferentes padrões e terminologias ${ }^{20}$.

Em seguida, traduzimos os termos para o inglês e realizamos a sua busca no BioPortal. As buscas foram registradas em planilhas específicas para cada um dos vocabulários. Assim, geramos quatro planilhas relativas ao RadLex, LOINC, SNOMED e OntoNeo.

Constatamos que nenhum dos quatro vocabulários atendem completamente aos termos levantados. Abaixo segue o Quadro 3, que traz a cobertura que os vocabulários consultados oferecem em relação à hierarquia que construímos:

Quadro 3. Porcentagem geral de termos recuperados

\begin{tabular}{|l|r|r|r|r|}
\hline & ONTONEO & RADLEX & \multicolumn{1}{|c|}{ LOINC } & SNOMED \\
\hline Total de termos & 218 & 218 & 218 & 218 \\
\hline Termos recuperados & 86 & 136 & 146 & 167 \\
\hline Termos não encontrados & 132 & 82 & 72 & 51 \\
\hline Cobertura dos termos recuperados & $39,45 \%$ & $62,39 \%$ & $66,96 \%$ & $76,61 \%$ \\
\hline
\end{tabular}

Fonte: Os autores (2018).

No Quadro 3, apresentamos uma coluna para cada vocabulário controlado em que buscamos os termos. Do total de termos (218), foram recuperados 86 no OntoNeo (aproximadamente 39,45\%); 136 no RadLex (aproximadamente 62,39\%); 146 no LOINC (aproximadamente 66,96\%); e, por fim, recuperamos 167 no SNOMED (aproximadamente 76,61\%). Dos 218, 30 (cerca de 13,75\%) não foram identificados em nenhum vocabulário controlado; são eles: A1; A1.4; A2.6.1; B1.2; B2.2; B4.2; C; C4.1; C7.1; D; D1.1; D1.2; D1.2.1.1; D1.2.1.2; D1.2.1.3; D1.3.1; D1.3.2; D1.3.3; D1.3.4; D2.1.1; D2.1.3; D2.1.4; D2.2.2; D2.2.3; D2.2.4; E1; E2.2; E2.3; E3.1.1; E4.5. Para fins de aplicação, este problema poderá ser solucionado via sugestões aos mantenedores das ontologias visitadas para incorporação de tais termos em seus respectivos produtos, ou ainda podem ser realizadas novas buscas em outros vocabulários controlados.

Se, por um lado, apenas 13,75\% dos termos não foram identificados em nenhum vocabulário consultado, por outro, apenas 78 termos estiveram presentes nas quatro ontologias, isto é, cerca de 35,78\%. Neste caso, encontramos os termos 'alterado' e 'normal' que se repetem 29 vezes cada (A1.2.1.1; A1.2.1.2; A1.3.1.1; A1.3.1.2; A1.4.1.1; A1.4.1.2; A1.5.1.1; A1.5.1.2; A2.1.1.1; A2.1.1.2; A2.2.1.1; A2.2.1.2; A2.3.1.1; A2.3.1.2; A2.4.1.1; A2.4.1.2; A2.5.1.1; A2.5.1.2; A2.5.2.1; A2.5.2.3; A2.7.1.1; A2.7.1.2; A2.8.1.1; A2.8.1.2; A2.9.1.1; A2.9.1.2; A2.10.1.1; A2.10.1.2; A2.11.1.1; A2.11.1.1; A2.12.1.1; A2.12.1.2; A2.13.1.1; A2.13.1.2; A2.14.1.1; A2.14.1.2; A2.15.1.1; A2.15.1.2; B1.1.1; B1.1.2; B1.2.1; B1.2.2; B2.1.1; B2.1.2; B2.2.1; B2.2.2; B3.1.1; B3.1.2; B3.2.1; B3.2.2; B4.1.1; B4.1.2; B4.2.1; B4.2.2; C8.1; C8.2; D1.2.1.4; D1.2.1.5), encontramos o termo 'comprimento' que se repete 11 vezes (A1.5.1; A2.2.1; A2.7.1; A2.8.1; A2.9.1; A2.10.1; A2.11.1; A2.12.1; A2.13.1; A2.14.1; A2.15.1), e, finalmente, os que apresentam apenas uma ocorrência: 'abdome' (A2.1); 'cerebelo' (A2.5); 'umbilical' (B1); 'genital' (C8); 'líquido amniótico' (D2); 'volume' (D2.1); 'qualidade de exame' (E2); 'datar gestação' (E4.4); 'sangramento' (E4.7). 
Como já relatado nesta seção do artigo, a decomposição dos termos nos permitiu identificar os mais relevantes (aqueles dos quais derivam outras informações) e os menos relevantes (aqueles que só apresentam sentido junto ao termo relevante, pois se referem a ele). Também há termos que revelam condições de manifestação daqueles mais relevantes e, ainda, termos que são categorias abstratas cuja função não é representar algo empírico, mas organizar logicamente nossa hierarquia. Assim verificamos que a contagem da porcentagem de cobertura dos termos por ontologia em função do tipo de termo teria impacto na análise do potencial representativo de cada uma das ontologias.

A seguir apresentaremos quatro quadros, cada um relativo à busca realizada em uma ontologia. Nos quadros, há quatro colunas que representam o tipo de termo estabelecido da seguinte maneira: CT representa as categorias abstratas cuja principal função é organizar logicamente a hierarquia; P representa os termos centrais mais relevantes dos quais fornecemos informações nos exames de radiologia obstétrica; $\mathrm{M}$ representa os modos, ou como os termos relevantes podem se manifestar; e, finalmente, F diz respeito aos termos menos relevantes em nossa hierarquia.

Quadro 4. Recuperação dos termos em tipos - OntoNeo

\begin{tabular}{|l|l|l|l|l|}
\hline \multicolumn{1}{|c|}{$\begin{array}{c}\text { Tipologia dos termos em nossa } \\
\text { classificação - OntoNeo }\end{array}$} & $\begin{array}{c}\text { Categorias } \\
\text { CT }\end{array}$ & $\begin{array}{c}\text { Classes } \\
\text { Principais P }\end{array}$ & Modos M & $\begin{array}{c}\text { Elementos } \\
\text { Finais F }\end{array}$ \\
\hline Total de termos na hierarquia & 5 & 44 & 63 & 106 \\
\hline Identificados nos vocabulários & 1 & 8 & 14 & 63 \\
\hline Termos não recuperados & 4 & 36 & 49 & 43 \\
\hline $\begin{array}{l}\text { Cobertura dos termos recuperados em } \\
\text { porcentagem }\end{array}$ & 20 & 18,1818182 & 22,2222222 & 59,4339623 \\
\hline
\end{tabular}

Fonte: Os autores (2018).

O Quadro 4 apresenta o vocabulário controlado que menos contempla nossas necessidades. Embora tal ontologia se proponha especificamente ao domínio de obstetrícia e neonatal, são poucas as suas contribuições. Talvez por ser ainda um vocabulário recente ${ }^{20}$ ou por ter um conjunto de termos reduzido (1343 segundo os dados no BioPortal). Verificamos que, em todas as tipologias de termos, a ontologia OntoNeo apresentou um baixo índice de recuperação, alcançando a quantidade de 1 de 5, 8 de 44, 14 de 63 e 63 de 106 possíveis em relação às tipologias CT, P, M e F, respectivamente. Mesmo o OntoNeo se propondo a um escopo mais aproximado da radiologia obstétrica, seus resultados são limitados na cobertura terminológica, correspondendo apenas a 39,45\%, como citamos anteriormente.

O RadLex apresentou índices mais interessantes, conforme explícito no Quadro 5.

Quadro 5. Recuperação dos termos em tipos - RadLex

\begin{tabular}{|l|c|c|c|c|}
\hline $\begin{array}{c}\text { Tipologia dos termos } \\
\text { em nossa classificação- } \\
\text { RadLex }\end{array}$ & $\begin{array}{c}\text { Categorias } \\
\text { CT }\end{array}$ & $\begin{array}{c}\text { Classes Principais } \\
\text { P }\end{array}$ & Modos M & $\begin{array}{c}\text { Elementos } \\
\text { Finais F }\end{array}$ \\
\hline Total de termos na hierarquia & 5 & 44 & 63 & 106 \\
\hline Identificados nos vocabulários & 2 & 25 & 37 & 72 \\
\hline Termos não recuperados & 3 & 19 & 26 & 34 \\
\hline $\begin{array}{l}\text { Cobertura dos termos } \\
\text { recuperados em porcentagem }\end{array}$ & 40 & 56,8181818 & 58,7301587 & 67,9245283 \\
\hline
\end{tabular}

Fonte: Os autores (2018). 
Relativo ao RadLex, o Quadro 5 revela que ele tem uma cobertura mais ampla que o OntoNeo. Essa ontologia focada na radiologia como um todo concentrou o maior número de termos recuperados na categoria A (ver Apêndice B), pois é nesta categoria que se encontra o conjunto de termos relacionados a partes do corpo, sobretudo os ossos que são fundamentais no acompanhamento do desenvolvimento do feto. A radiologia também é centrada na produção de exames relacionados a este tecido. O Quadro 5 revela um aumento nos índices de recuperação em todos os tipos de termos em relação ao OntoNeo. Os números são 2 de 5, 25 de 44, 37 de 63 e 72 de 106 em relação às tipologias CT, P, M e F, respectivamente.

Os resultados obtidos ao verificarmos a cobertura dos termos de nossa hierarquia no LOINC seguem no Quadro 6.

Quadro 6. Recuperação dos termos em tipos - LOINC

\begin{tabular}{|l|c|c|c|c|}
\hline $\begin{array}{c}\text { Tipologia dos termos em nossa } \\
\text { classificação - LOINC }\end{array}$ & Categorias CT & $\begin{array}{c}\text { Classes } \\
\text { Principais P }\end{array}$ & Modos M & $\begin{array}{c}\text { Elementos } \\
\text { Finais F }\end{array}$ \\
\hline Total de termos na hierarquia & 5 & 44 & 63 & 106 \\
\hline Identificados nos vocabulários & 2 & 33 & 40 & 71 \\
\hline Termos não recuperados & 3 & 11 & 23 & 35 \\
\hline $\begin{array}{l}\text { Cobertura dos termos recuperados } \\
\text { em porcentagem }\end{array}$ & 40 & 75 & 63,4920635 & 66,9811321 \\
\hline
\end{tabular}

Fonte: Os autores (2018).

Apresentando 66,96\% de cobertura total, o LOINC é uma grande ontologia, com 192372 classes, e desde 2009 sofre constantes atualizações, segundo o BioPortal. Os resultados relativos aos tipos dos termos CT, P, M e F são respectivamente 2 de 5, 33 de 44, 40 de 63 e 71 de 106. As porcentagens de cada um desses resultados apresentam certo equilíbrio, assim como já aconteceu no RadLex; contudo, com índices mais altos, apresentando $40 \%$ de recuperação de CT, $75 \%$ de $\mathrm{P}, 63,5 \%$ de $\mathrm{M}$ e praticamente $67 \%$ de $\mathrm{F}$, enquanto que o RadLex apresentou 40\%, 56,7\%, 58,6\% e 63,8\% em relação aos mesmos tipos de termos.

O Quadro 7 abarca os dados relativos à cobertura dos termos de nossa hierarquia no SNOMED.

Quadro 7. Recuperação dos termos em tipos - SNOMED

\begin{tabular}{|l|c|c|c|c|}
\hline \multicolumn{1}{|c|}{$\begin{array}{c}\text { Tipologia dos termos em nossa } \\
\text { classificação - SNOMED }\end{array}$} & $\begin{array}{c}\text { Categorias } \\
\text { CT }\end{array}$ & $\begin{array}{c}\text { Classes } \\
\text { Principais P }\end{array}$ & Modos M & $\begin{array}{c}\text { Elementos } \\
\text { Finais F }\end{array}$ \\
\hline Total de termos na hierarquia & 5 & 44 & 63 & 106 \\
\hline Identificados nos vocabulários & 2 & 35 & 47 & 83 \\
\hline Termos não recuperados & 3 & 9 & 16 & 23 \\
\hline $\begin{array}{l}\text { Cobertura dos termos recuperados } \\
\text { em porcentagem }\end{array}$ & 40 & 79,5454545 & 74,6031746 & 78,3018868 \\
\hline
\end{tabular}

Fonte: Os autores (2018).

Por fim, o SNOMED. Com cerca de 327128 classes, entre as quais 32114 apresentam um único filho (subclasse) e 2500 apresentam mais que 25 filhos, sua amplitude interfere também em nosso resultado. $\mathrm{O}$ SNOMED foi o vocabulário com maior cobertura de nossas necessidades, recuperando 2 de 5, 35 de 44, 47 de 63 e 83 de 106, relativos às categorias CT, $\mathrm{P}, \mathrm{M} \mathrm{e} \mathrm{F}$, respectivamente. As porcentagens se apresentam bastante 
equilibradas. Seguindo a mesma ordem de apresentação dos índices de recuperação, as porcentagens foram 40\%, 79,4\%, 74,5\% e 78,2\%. Embora o foco deste artigo não seja a questão semântica, destacamos que, no SNOMED, o índice de recuperação do tipo de termo $\mathrm{P}$ é o mais alto, o que pode ser um indicativo de convergências mais profícuas entre nossas necessidades e a ontologia em questão.

O SNOMED é destacado como um vocabulário diferenciado por sua abrangência, recomendando-o no uso conjunto com o padrão ${ }^{7}$. Nossos resultados revelam que tal vocabulário mostrou-se mais adequado para sanar nossas necessidades terminológicas; contudo, ainda necessitamos aprofundar os estudos no que concerne aos aspectos semânticos.

\section{Considerações finais}

Em um primeiro momento, a pesquisa aqui apresentada centrou-se no levantamento de termos a partir de um banco de dados em Microsoft Access e de reuniões com um especialista. Os termos foram selecionados e arranjados hierarquicamente. Nesse arranjo, não nos preocupamos com o critério de redundância pois, além da hierarquia, a função final da pesquisa foi estruturar laudos da radiologia obstétrica no Sistema Integrado Catarinense de Telemedicina e Telessaúde (STT/SC). Essa etapa aconteceu com constantes reuniões com especialista da referida área no Hospital Universitário da Universidade Federal de Santa Catarina. Essa hierarquia apresentada no Apêndice B revela categorias abstratas cuja função é apenas permitir o arranjo lógico dos termos. As subclasses derivadas dessas hierarquias são elementos relativos aos exames de radiologia obstétrica, e representam instâncias empíricas ou manifestações possíveis dessas instâncias. Ainda há as últimas subclasses, chamadas de folhas por estarem na extremidade da árvore, em que grande parte representa um conjunto de resultados possíveis dos exames. Assim, termos 'normal' e 'alterado', 'presente' e 'ausente' e 'regular' e 'irregular' como um conjunto de termos serão especificados em pesquisas futuras.

O padrão DICOM permite o uso conjunto de vários vocabulários controlados. Em uma segunda etapa foram selecionados quatro vocabulários específicos: o OntoNeo, o RadLex, o LOINC e o SNOMED. Todos são acessíveis via o BioPortal, no qual há um sistema de busca que utilizamos com o objetivo de realizar a pesquisa documental. Nessa busca, contatamos que o SNOMED cobriu 76,61\% dos termos levantados na primeira etapa da pesquisa. O LOINC foi o segundo vocabulário com maior cobertura, abrangendo cerca de 66,96\%, seguido pelo RadLex, que cobriu 62,39\% e, por fim, o OntoNeo com cobertura de 39,45\%. Constatamos que o volume do vocabulário interferiu de forma decisiva, suplantando outros critérios como escopo ou idade do vocabulário.

Embora o objetivo deste artigo não passe pelo estudo semântico dos termos, verificamos que em nossa hierarquia de referência há tipos distintos de termos que indicam maiores possibilidades de convergência ou divergência entre eles e os vocabulários consultados via BioPortal. Assim, geramos os tipos 'categoria' (CT), 'classe principal' (P), 'modo' (M) e 'elementos finais' (F), entre os quais constatamos que P é o tipo de maior valor, seguido por $\mathrm{M}$, pois são termos que representam os objetos empíricos, focos da ação médica. Buscando a cobertura por tipos de termos, identificamos que o SNOMED é o vocabulário com maior revocação dos termos P e M, seguido pelo LOINC, RadLex e, por último, o OntoNeo.

Os baixos índices de revocação no OntoNeo são um resultado pouco esperado, devido ao domínio a que a ontologia se destina, próximo semanticamente ao domínio selecionado para essa pesquisa. É provável que tal resultado se justifique pela recente formalização desse vocabulário ${ }^{18}$. Contudo, outro fator que pode interferir nos resultados é a divergência terminológica entre os termos procurados e os contidos na estrutura do vocabulário. Seria relevante aprofundar um estudo nessa direção.

Ao longo da pesquisa, as dificuldades enfrentadas foram: a questão terminológica, no que diz respeito à definição dos termos de modo que estes correspondam ao uso corrente; a questão de tradução desses 
termos para o inglês para efetivação da busca; as variações morfológicas; variações de número; variações de classes gramaticais, variações sintáticas, a ordenação das palavras em termos compostos, entre outras manifestações que interferem não só na identificação e reconhecimento, mas também na validação semântica de cada termo. A questão semântica será aprofundada em trabalhos futuros.

Tais questões serão aprofundadas em futuras publicações decorrentes dessa mesma pesquisa. Esperamos que este artigo traga contribuições na interface comum entre ciência da informação, ciência da computação e a área médica, ramo interdisciplinar do conhecimento que vem sendo reconhecido pelo desígnio de informação em saúde. E ainda, que contribua também com a comunicação de conteúdo transferido cotidianamente no STT/SC.

\section{Referências}

1. Moraes IH, Santos SR. Informação em saúde: os desafios continuam. Ci Saúde Coletiva. 1998 [citado em 2017 jul. 13];3(1):37-51. http://dx.doi.org/10.1590/1413-812319983102772014

2. Telessaúde Santa Catarina [Internet]. Histórico; 2017 [citado em 2018 fev. 27]. Disponível em: http:// telessaude.ufsc.br/historico/

3. Savaris $A$, Andrade R, Macedo DD, Von Wangenheim A. O uso da telemedicina assistencial assíncrona em larga escala no setor público de saúde. In: $11^{\circ}$ Congresso Brasileiro de Informática em Saúde; 2008 29 nov.-03 dez.; Campos do Jordão, SP. São Paulo: SBI; 2008.

4. Shimizu S, Nakashima N, Okamura K, Tanaka M. One hundred case studies of Asia-Pacific telemedicine using a digital video transport system over a research and education network. Telemed J E-Health. 2009 [citado em 2017 jul. 13];15(1):112-7. https://doi.org/10.1089/tmj.2008.0067

5. Picchi Netto O, Macedo AA, de Azevedo Marques PM, Baranauskas JA. Uma metodologia para estruturação de laudos médicos usando ontologias. In: $11^{\circ}$ Workshop de Informática Médica; $30^{\circ}$ Congresso da Sociedade Brasileira de Computação; 2011 19-20 jul.; Natal, RN. Natal: UFRN; 2011.

6. Morioka CA, Sinha U, Taira R, El Saden SU, Duckwiler G, Kangarloo H. Structured reporting in neuroradiology. Ann NY Acad Sci. 2002 Dec 1 [citado em 2017 jul. 13];980(1):259-66. https://doi. org/10.1111/j.1749-6632.2002.tb04902.x

7. Chennamsetty H, Chalasani S, Riley D. Predictive analytics on Electronic Health Records (EHRs) using Hadoop and Hive. In: 2015 IEEE International Conference on Electrical, Computer and Communication Technologies; 2015 05-07 Mar; Coimbatore, India. Nova Jersey: IEEE; 2015.

8. Clunie DA. DICOM structured reporting. Bangor, Pennsylvania: PixelMed Publishing; 2000.

9. Tálamo MD, de Lara ML, Kobashi NY. Vamos perseguir a informação. Comun Educ. 1995 dez. [citado em 2017 jul. 13];30(4):52-7. http://dx.doi.org/10.11606/issn.2316-9125.v0i4p52-57

10. Dahlberg I. Teoria da classificação, ontem e hoje. In: Anais da Conferência Brasileira de Classificação Bibliográfica; 1976 set. 12-17; Rio de Janeiro: IBICT/ABDF, 1979. p.352-370.

11. Santarem Segundo JE, Coneglian CS. Web semântica e ontologias: um estudo sobre construção de axiomas e uso de inferências. Inf Inf. 2016 [citado em 2017 jul. 13]; 21(2): 217-44. http://dx.doi. org/10.5433/1981-8920.2016v21n2p217

12. Bräscher M, Carlan E. Sistemas de organização do conhecimento: antigas e novas linguagens. In: Robredo J, Bräscher M. Passeios no Bosque da Informação: estudos sobre representação e organização da informação e do conhecimento. Brasília, DF: IBICT; 2010. p.147-76.

13. Noy NF, Shah NH, Whetzel PL, Dai B, Dorf M, Griffith N, et al. BioPortal: ontologies and integrated data resources at the click of a mouse. Nucleic Acids Research. 2009; 37(suppl 2):W170-3. https://doi. org/10.1093/nar/gkp440

14. Andrade JD. Interoperabilidade e mapeamentos entre sistemas de organização do conhecimento na busca e recuperação de informações em saúde: estudo de caso em ortopedia e traumatologia [tese]. São Paulo: Universidade de São Paulo; 2015.

15. Creswell JW. Projeto de pesquisa métodos qualitativo, quantitativo e misto. 3. ed. Porto Alegre: Artmed; 2010. 
16. Lakatos EM, Marconi MD. Fundamentos da metodologia científica. São Paulo: Atlas; 1991.

17. Radiological Society of North America [Internet]. RadLex: about. 2017 [citado em 2017 maio 13]. Disponível em: https://www.rsna.org/RadLex.aspx

18. Chen ES, Melton GB, Engelstad ME, Sarkar IN. Standardizing clinical document names using the HL7/ LOINC document ontology and LOINC codes. AMIA Annu Symp Proc; 2010 Nov [citado em 2017 jul. 13];2010(2010):101-5. Disponível em: https://www.ncbi.nlm.nih.gov/pmc/articles/PMC3041326/

19. Girão IPT; Rabelo CRO; Pinto VB. SNOMED-CT as Standard Lan-guage for Organization and Representation of the Information in Patient Records. Knowl Organ [Internet]. 2014 [citado em 2017 maio 04];41(4):311-8. Disponível em: http://www.repositorio.ufc.br/ri/handle/riufc/19136

20. Farinellia F, Almeida MB, Elkin PL, Smith B. Medical encounters in the obstetric and neonatal domain: an approach based on ontological realism. In: Joint International Conference on Biological Ontology and BioCreative; 2016 Aug 1-6; Corvallis, Oregon. Oregon State University: ICBO; 2016. 


\section{Apêndice A}

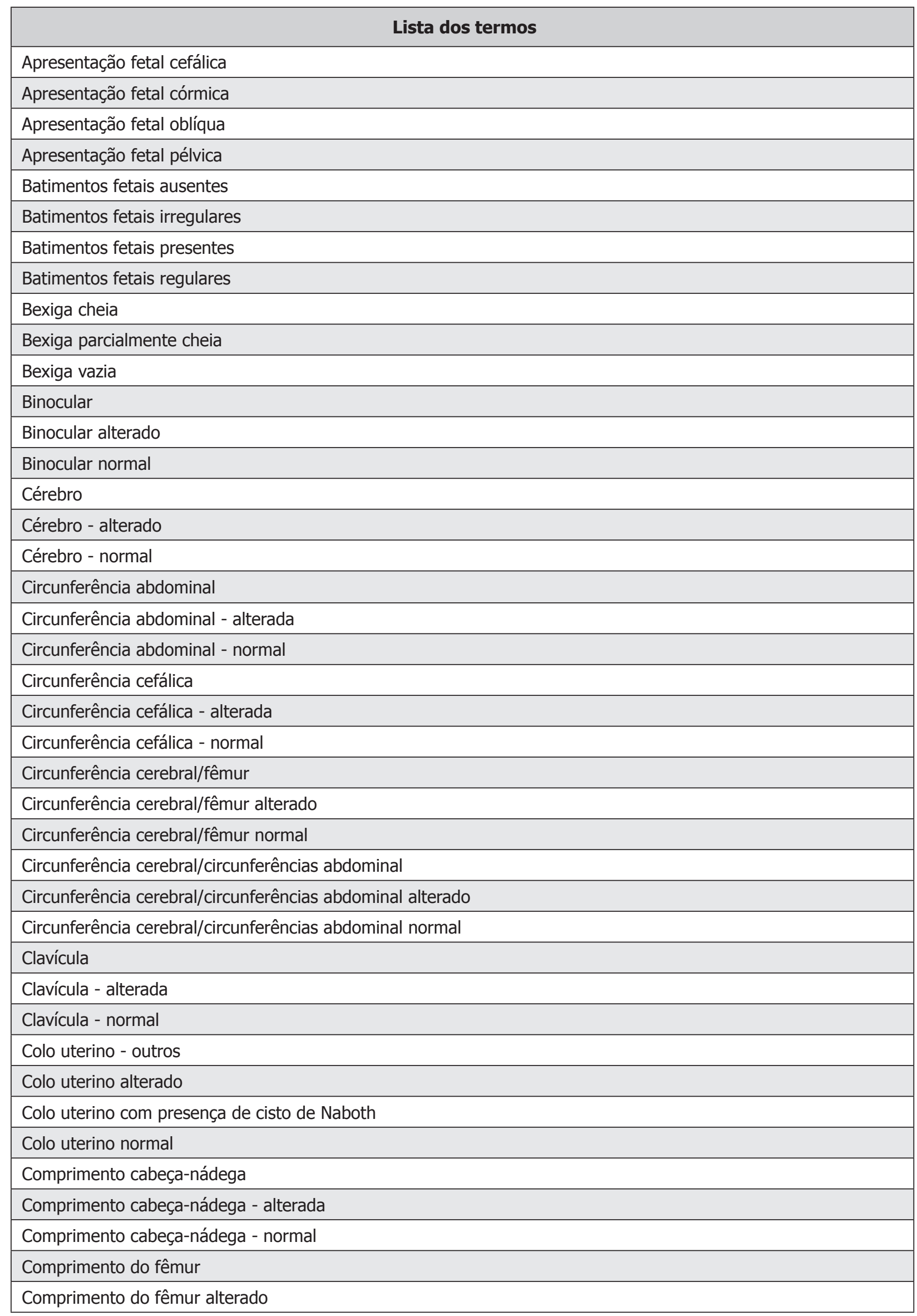




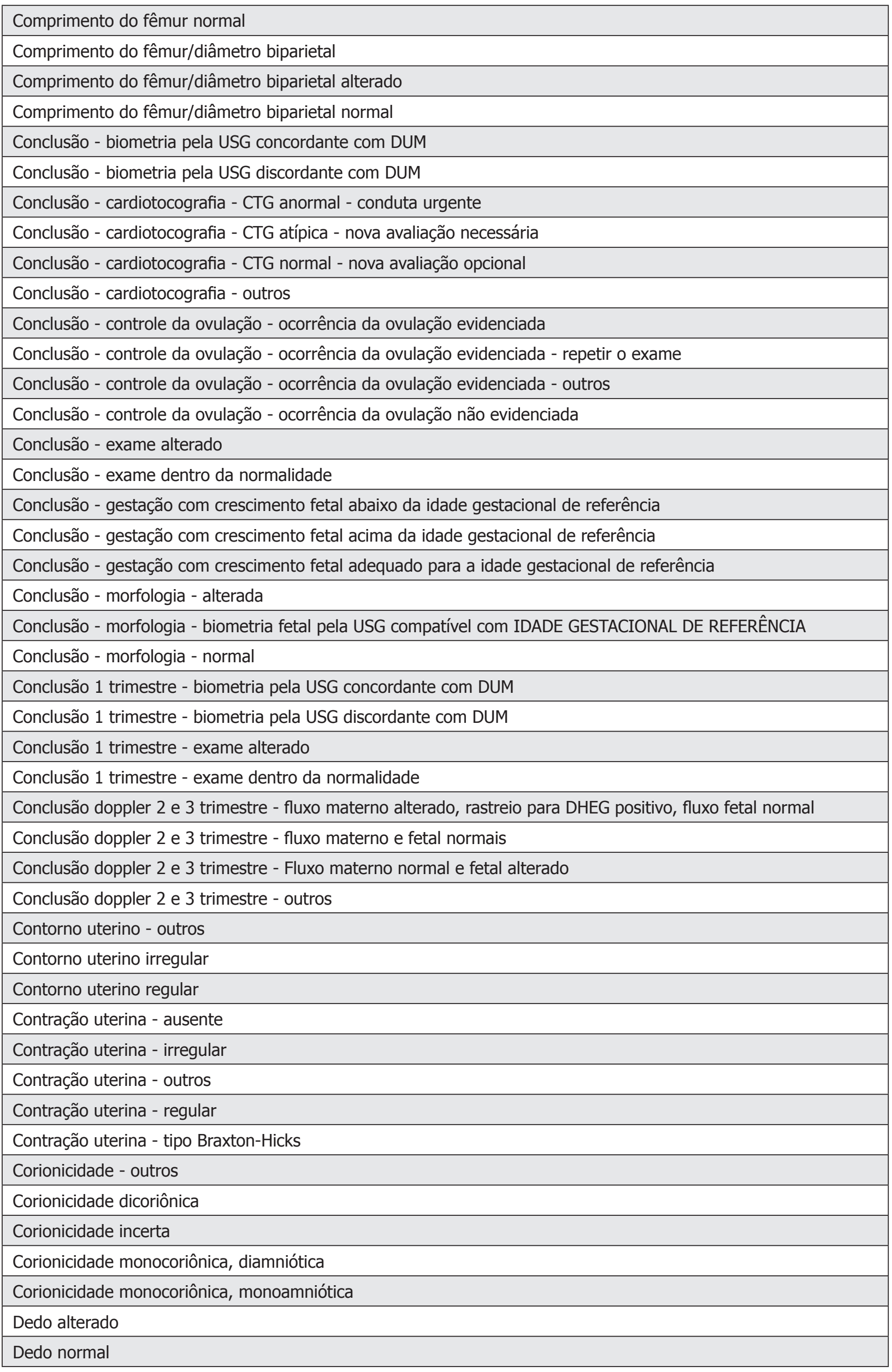




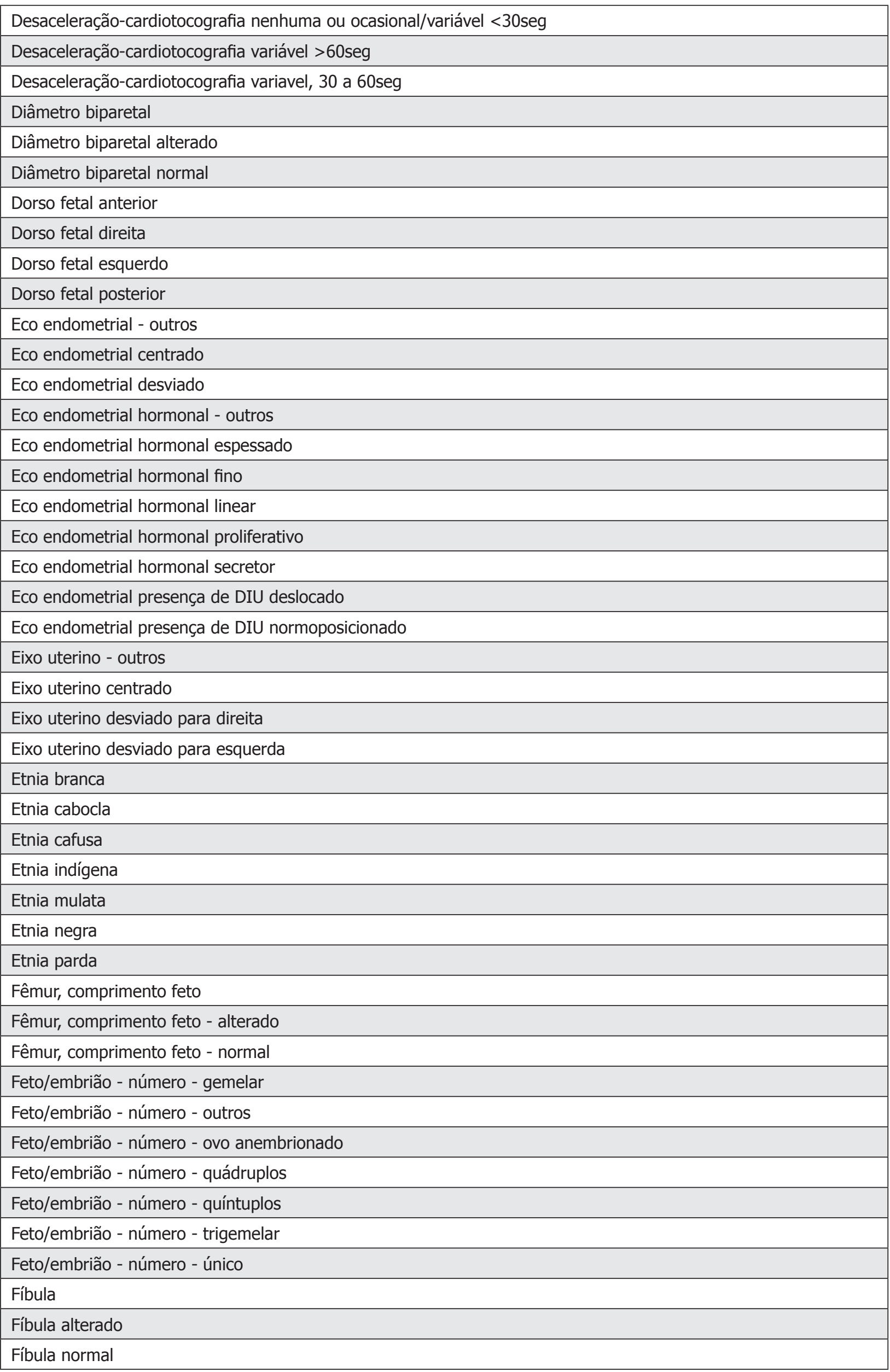




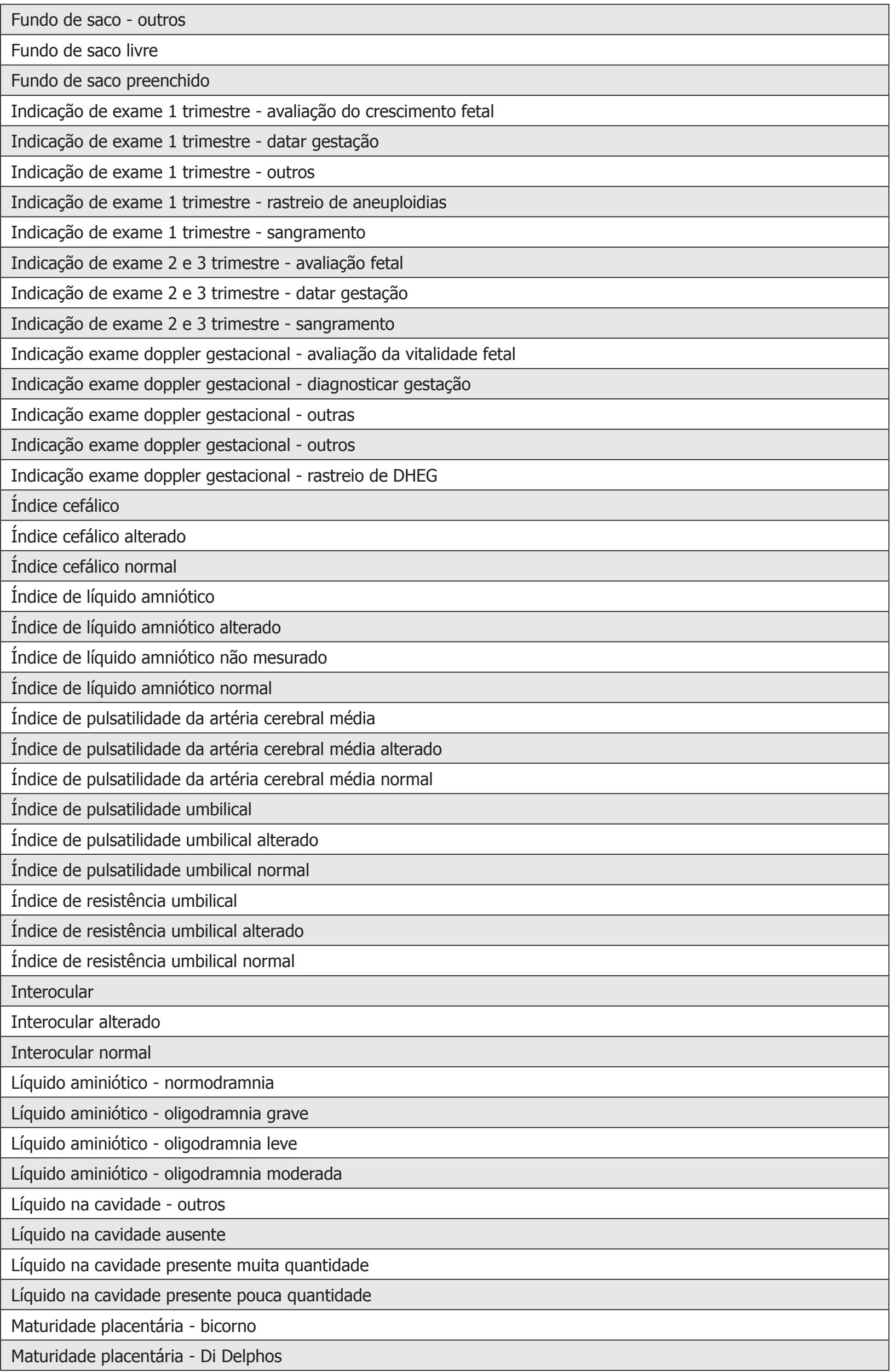




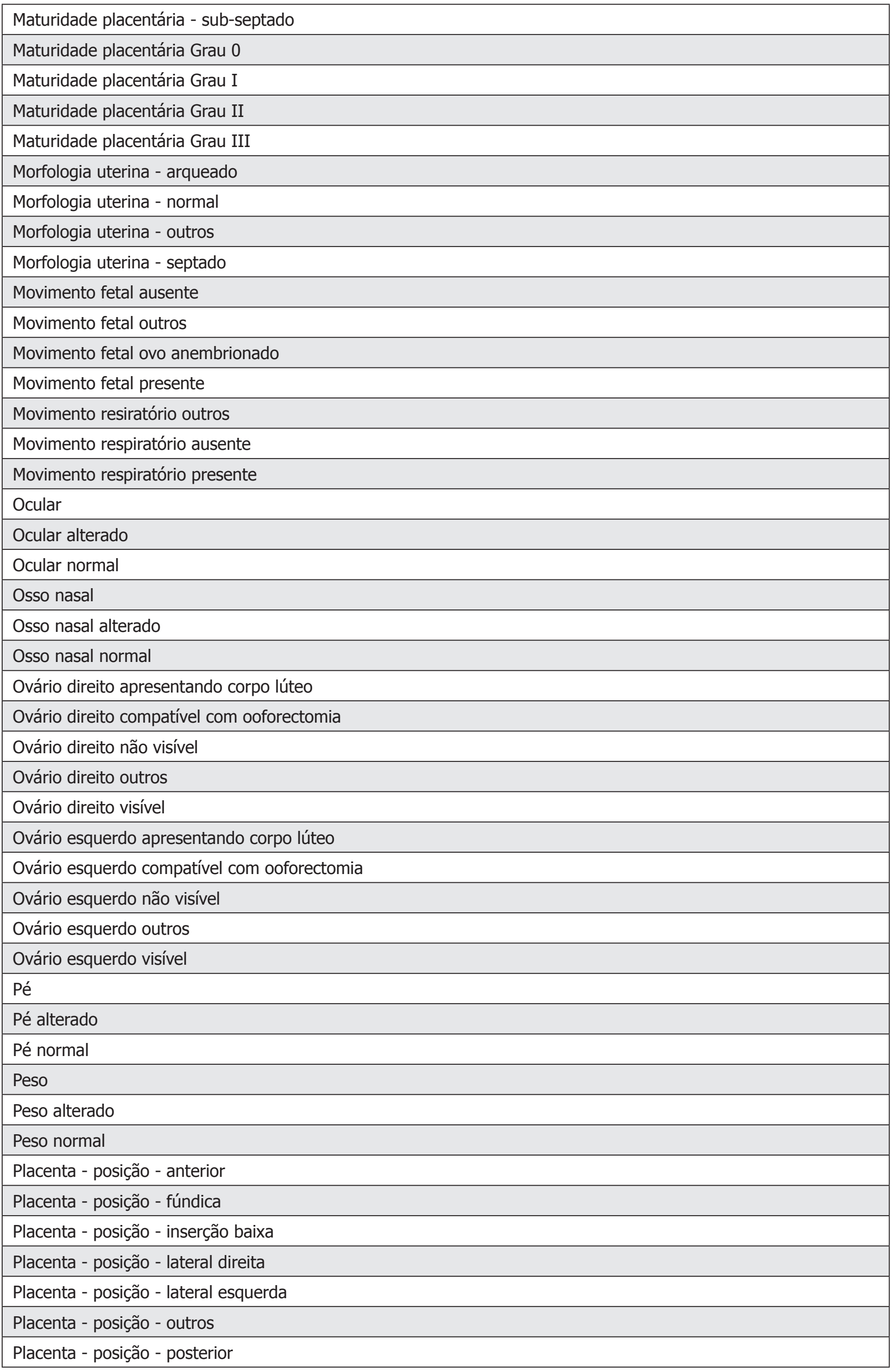




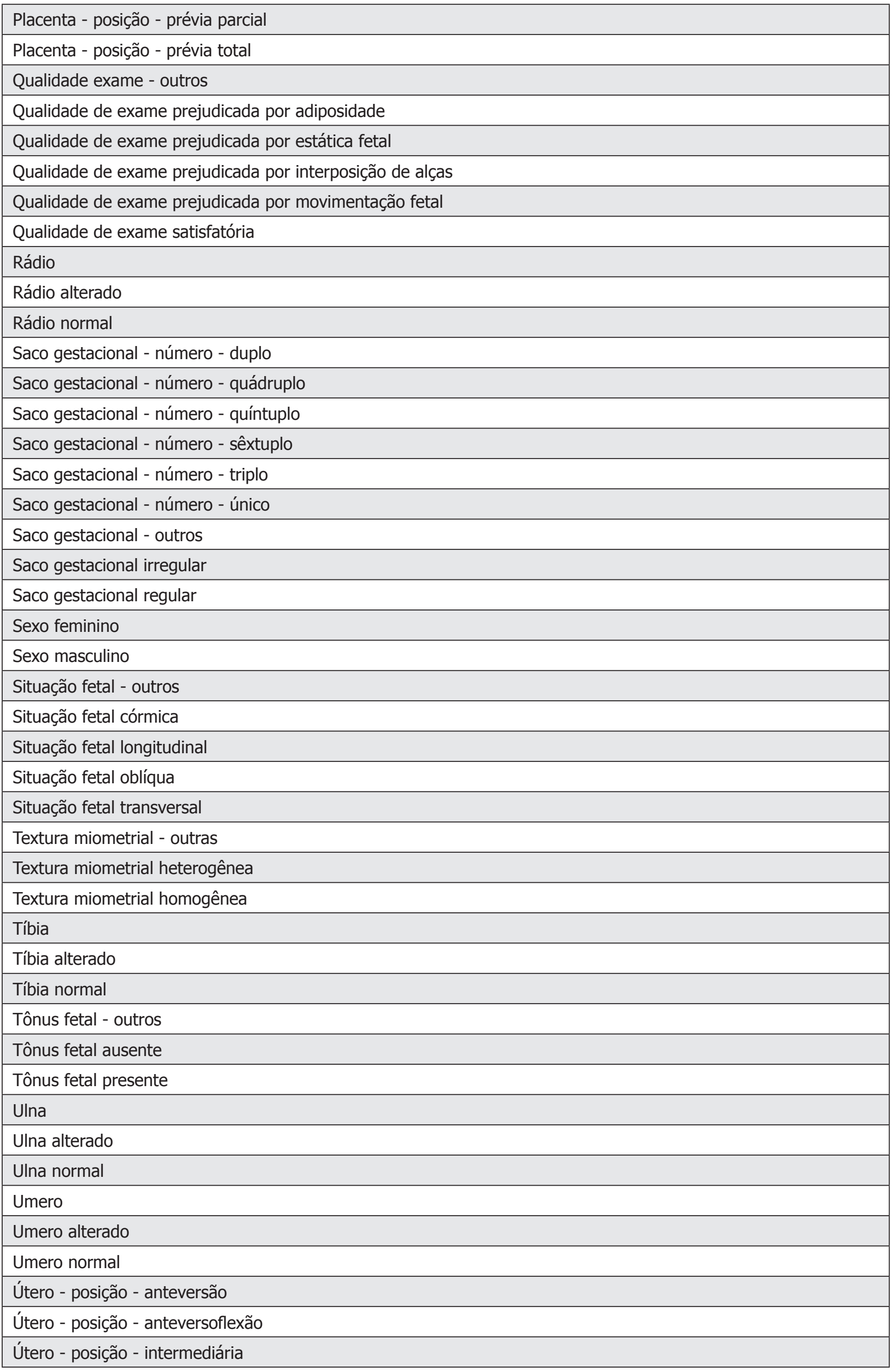




\begin{tabular}{|l|}
\hline Útero - posição - outros \\
\hline Útero - posição - retroversão \\
\hline Útero - posição - retroversoflexão \\
\hline Variabilidade - cardiotocografia 5 bpm ou $25 \mathrm{bpm}$ \\
\hline Variabilidade - cardiotocografia 5 bpm por 40 a $80 \mathrm{~min}$ \\
\hline Variabilidade - cardiotocografia 6 a 25 bpm \\
\hline Via de exame abdominal \\
\hline Via de exame transvaginal \\
\hline Volume uterino - outros \\
\hline Volume uterino alterado \\
\hline Volume uterino aumentado \\
\hline Volume uterino diminuído \\
\hline Volume uterino normal \\
\hline
\end{tabular}




\section{Apêndice $B$}

\begin{tabular}{|c|c|}
\hline $\mathbf{A}$ & Morfologia \\
\hline $\mathrm{A} 1$ & Medida facial \\
\hline A12 & Binocular \\
\hline $\mathrm{A} 121$ & distância \\
\hline A1211 & alterado \\
\hline A1212 & normal \\
\hline A13 & Interocular \\
\hline A131 & distância \\
\hline A1311 & alterada \\
\hline A1312 & normal \\
\hline A14 & Ocular \\
\hline A141 & diâmetro \\
\hline A1411 & alterada \\
\hline A1412 & normal \\
\hline A15 & Osso nasal \\
\hline $\mathrm{A} 151$ & comprimento \\
\hline A1511 & alterada \\
\hline A1512 & normal \\
\hline $\mathrm{A} 2$ & Biometria fetal \\
\hline $\mathrm{A} 21$ & Abdome \\
\hline A211 & circunferência \\
\hline $\mathrm{A} 2111$ & alterado \\
\hline A2112 & normal \\
\hline $\mathrm{A} 22$ & Cabeça-nádega \\
\hline $\mathrm{A} 221$ & comprimento \\
\hline A2211 & alterada \\
\hline A2212 & normal \\
\hline A23 & Biparietal \\
\hline A231 & diâmetro \\
\hline A2311 & alterada \\
\hline A2312 & normal \\
\hline A24 & Cefálica \\
\hline A241 & circunferência \\
\hline A2411 & alterado \\
\hline A2412 & normal \\
\hline A25 & Cerebelo \\
\hline$A 251$ & diâmetro transveso \\
\hline A2511 & alterada \\
\hline A2512 & normal \\
\hline A252 & cisterna magna \\
\hline A2521 & alterada \\
\hline A2522 & diminuído \\
\hline A2523 & normal \\
\hline
\end{tabular}




\begin{tabular}{|c|c|}
\hline A26 & Saco gestacional \\
\hline A261 & condição \\
\hline A2611 & irregular \\
\hline A2612 & regular \\
\hline$A 27$ & Fêmur \\
\hline A271 & comprimento \\
\hline A2711 & alterada \\
\hline A2712 & normal \\
\hline A28 & Clavícula \\
\hline A281 & comprimento \\
\hline A2811 & alterada \\
\hline A2812 & normal \\
\hline A29 & Fíbula \\
\hline A291 & comprimento \\
\hline A2911 & alterada \\
\hline A2912 & normal \\
\hline A210 & Dedo \\
\hline A2101 & comprimento \\
\hline A21011 & alterada \\
\hline A21012 & normal \\
\hline A211 & Pé \\
\hline A2111 & comprimento \\
\hline A21111 & alterada \\
\hline A21111 & normal \\
\hline A212 & Rádio \\
\hline A2121 & comprimento \\
\hline A21211 & alterado \\
\hline A21212 & normal \\
\hline A213 & Tíbia \\
\hline A2131 & comprimento \\
\hline A21311 & alterada \\
\hline A21312 & normal \\
\hline A214 & Ulna \\
\hline A2141 & comprimento \\
\hline A21411 & alterada \\
\hline A21412 & normal \\
\hline$A 215$ & Umero \\
\hline A2151 & comprimento \\
\hline A21511 & alterada \\
\hline A21512 & Normal \\
\hline B & Doppler \\
\hline B1 & Umbilical \\
\hline B11 & pulsatilidade \\
\hline B111 & alterada \\
\hline B112 & normal \\
\hline
\end{tabular}




\begin{tabular}{|c|c|}
\hline B12 & resistência \\
\hline B121 & alterada \\
\hline B122 & normal \\
\hline B2 & Cerebral \\
\hline B21 & pulsatilidade \\
\hline B211 & alterada \\
\hline B212 & normal \\
\hline B22 & resistência \\
\hline B221 & alterada \\
\hline B222 & normal \\
\hline B3 & Ducto venoso \\
\hline B31 & pulsatilidade \\
\hline B311 & alterada \\
\hline B312 & normal \\
\hline B32 & relação atrioventricular \\
\hline B321 & alterada \\
\hline B322 & normal \\
\hline B4 & Artéria ulterina \\
\hline B41 & pulsatilidade \\
\hline B411 & alterada \\
\hline B412 & normal \\
\hline B42 & resistência \\
\hline B421 & alterada \\
\hline B422 & normal \\
\hline C & Estática e bem estar fetal \\
\hline $\mathrm{C} 1$ & Dorso \\
\hline $\mathrm{C} 11$ & anterior \\
\hline $\mathrm{C} 12$ & direito \\
\hline $\mathrm{C} 13$ & esquerdo \\
\hline $\mathrm{C} 14$ & posterior \\
\hline $\mathrm{C} 2$ & Tônus \\
\hline $\mathrm{C} 21$ & ausente \\
\hline $\mathrm{C} 22$ & presente \\
\hline $\mathrm{C} 3$ & Apresentação \\
\hline $\mathrm{C} 31$ & cefálica \\
\hline $\mathrm{C} 32$ & córmica \\
\hline $\mathrm{C} 33$ & oblíqua \\
\hline $\mathrm{C} 34$ & pélvica \\
\hline C4 & Posição \\
\hline C41 & córmica \\
\hline $\mathrm{C} 42$ & transversal \\
\hline $\mathrm{C} 43$ & oblíqua \\
\hline $\mathrm{C} 44$ & longetudinal \\
\hline $\mathrm{C} 5$ & Batimento cardíaco fetal \\
\hline $\mathrm{C} 51$ & ausentes \\
\hline
\end{tabular}




\begin{tabular}{|c|c|}
\hline C52 & irregulares \\
\hline C53 & presentes \\
\hline C54 & regulares \\
\hline C6 & Cardiotocografia \\
\hline C61 & desaceleração \\
\hline C611 & nenhuma ou ocasional/variável $<30$ seg \\
\hline C612 & variável >60seg \\
\hline C613 & variavel 30 a $60 \mathrm{seg}$ \\
\hline C62 & variabilidade \\
\hline C621 & 5 bpm ou $25 \mathrm{bpm}$ \\
\hline C622 & 5 bpm por 40 a $80 \mathrm{~min}$ \\
\hline C623 & 6 a 25 bpm \\
\hline C63 & conclusão \\
\hline C631 & CTG anormal - conduta urgente \\
\hline C632 & CTG atípica - nova avaliação necessária \\
\hline C633 & CTG normal - nova avaliação opcional \\
\hline $\mathrm{C7}$ & Movimento \\
\hline C71 & corporal \\
\hline C711 & ausente \\
\hline C712 & presente \\
\hline C713 & ovo anembrionado \\
\hline $\mathrm{C} 72$ & respiratório \\
\hline C721 & ausente \\
\hline $\mathrm{C} 722$ & presente \\
\hline $\mathrm{C} 8$ & Genital \\
\hline C81 & alterado \\
\hline C82 & normal \\
\hline D & Anexo fetal \\
\hline D1 & Placenta \\
\hline D11 & corionicidade \\
\hline D111 & dicoriônica \\
\hline D112 & incerta \\
\hline D113 & monocoriônica \\
\hline D12 & Amniocidade \\
\hline D121 & quantidade \\
\hline D1211 & monoamniótico \\
\hline D1212 & diamniótico \\
\hline D1213 & triamniótico \\
\hline D1214 & alterada \\
\hline D1215 & normal \\
\hline D13 & Maturidade \\
\hline D131 & granum 0 \\
\hline D132 & granum I \\
\hline D133 & granum II \\
\hline D134 & granum III \\
\hline
\end{tabular}




\begin{tabular}{|c|c|}
\hline D2 & Liquido amniótico \\
\hline D21 & volume \\
\hline D211 & normodramnia \\
\hline D212 & oligodramnia grave \\
\hline D213 & oligodramnia leve \\
\hline D214 & oligodramnia moderada \\
\hline D215 & aumentado \\
\hline D216 & diminuído \\
\hline D22 & Índice de Líquido Aminiótico (ILA) \\
\hline D221 & oligodramnia grave \\
\hline D222 & oligodramnia leve \\
\hline D223 & oligodramnia moderada \\
\hline D224 & polidraminia \\
\hline E & Exame \\
\hline E1 & via de exame \\
\hline E11 & abdominal \\
\hline E12 & transvaginal \\
\hline E2 & qualidade de exame \\
\hline E21 & prejudicado por adiposidade \\
\hline E22 & prejudicado por estática fetal \\
\hline E23 & prejudicado por interposição de alças \\
\hline E24 & prejudicado por movimentação fetal \\
\hline E25 & satisfatória \\
\hline E3 & gestação \\
\hline E31 & quantidade \\
\hline E311 & único \\
\hline E312 & gemelar \\
\hline E313 & trigemelar \\
\hline E314 & quádruplos \\
\hline E315 & quíntuplos \\
\hline E316 & sêxtuplos \\
\hline E317 & óctuplos \\
\hline E4 & indicação \\
\hline E41 & avaliação da vitalidade fetal \\
\hline $\mathrm{E} 42$ & avaliação do crescimento fetal \\
\hline E43 & diagnosticar gestação \\
\hline E44 & datar gestação \\
\hline E45 & rastreio de DHEG \\
\hline E46 & rastreio de aneuploldias \\
\hline E47 & sangramento \\
\hline
\end{tabular}

